\title{
Ingeniería para la gente
}

Eliana Zapata Ruiz ${ }^{1}$

\section{OPEN ACCESS}

\section{(c) $(\Phi \otimes \Theta$}

Copyright:(C) 2019 Ingenierías USBmed. La revista Ingenierías USBmed proporciona acceso abierto a todos sus contenidos bajo los términos de la licencia creative commons Atribución- no comercial- SinDerivar 4.0 Internacional (CC BY-NC-ND 4.0)

Editores: Yohana López Rivera, Universidad de San Buenaventura, Medellín, Colombia. Alfonso Insuasti Rodríguez, Universidad de San Buenaventura, Medellín, Colombia. Erika Solange Imbett Vargas, Instituto Tecnológico Metropolitano. Eliana Zapata Ruiz, Instituto Tecnológico Metropolitano. José Fernando Valencia Grajales, Universidad Autónoma Latinoamericana.

\author{
${ }^{1}$ Ingeniera en Diseño Industrial, Facultad de Artes y Humanidades, \\ Instituto Tecnológico Metropolitano, Medellín, Colombia. \\ Email: elianazapata@itm.edu.co.
}

La ingeniería lleva en sus raíces la habilidad que tenemos los seres humanos para generar con ingenio y creatividad soluciones a problemas específicos. En un contexto sumergido en la vulneración constante de los derechos humanos como el de Colombia, se hace necesario orientar el saber tecnológico y profesional, desde el ejercicio académico, hacia la generación de soluciones tecnológicas para las diversas problemáticas sociales que aquejan al país.

Esta construcción de conocimiento orientado al desarrollo territorial desde los ámbitos sociales y ambientales, enmarcada en una política de ciencia abierta en construcción, busca que se formulen, ejecuten y divulguen proyectos de carácter social y sostenible, que conversen con las comunidades - y comprendan el entorno en que se encuentran-, para generar un tipo de desarrollo alternativo en el que las comunidades no se vean afectadas, sino más bien incluidas, en busca de reconstruir el tejido social que promueve, en último término, el mejoramiento de la calidad de vida de las personas y las regiones en las que habitan.

Esta edición compartida entre las Universidades de San Buenaventura y Autónoma Latinoamericana, el Instituto Tecnológico Metropolitano y la revista Kavilando tiene como objetivo propiciar un espacio de discusión, análisis y proposición en torno a temáticas como ciencia abierta, tecnologías para la transformación regional, sostenibilidad ambiental, transición energética y desarrollo territorial, con el fin de reorientar la profesión ingenieril de nuevo al servicio de la sociedad, bajo el reconocimiento de que la academia debe dirigir el conocimiento a fortalecer lo humano, incluso desde lo técnico. 